\title{
Corrigendum to "Stabilizing Parametric Region of Multiloop PID Controllers for Multivariable Systems Based on Equivalent Transfer Function"
}

\author{
Xiaoli Luan, ${ }^{1}$ Qiang Chen, ${ }^{1}$ Pedro Albertos, ${ }^{2}$ and Fei Liu ${ }^{1}$ \\ ${ }^{1}$ Key Laboratory of Advanced Process Control for Light Industry, Ministry of Education and the Institute of Automation, \\ Jiangnan University, Wuxi 214122, China \\ ${ }^{2}$ Department of System Engineering and Automatica, Universidad Politécnica de Valencia, 46022 Valencia, Spain \\ Correspondence should be addressed to Pedro Albertos; pedro@aii.upv.es \\ Received 4 June 2017; Accepted 27 June 2017; Published 13 July 2017 \\ Copyright (c) 2017 Xiaoli Luan et al. This is an open access article distributed under the Creative Commons Attribution License, \\ which permits unrestricted use, distribution, and reproduction in any medium, provided the original work is properly cited.
}

In the article titled "Stabilizing Parametric Region of Multiloop PID Controllers for Multivariable Systems Based on Equivalent Transfer Function," [1] affiliation number two was given incorrectly. The corrected affiliation is shown above.

\section{References}

[1] X. Luan, Q. Chen, P. Albertos, and F. Liu, "Stabilizing parametric region of multiloop PID controllers for multivariable systems based on equivalent transfer function," Mathematical Problems in Engineering, vol. 2016, Article ID 3173289, 7 pages, 2016. 


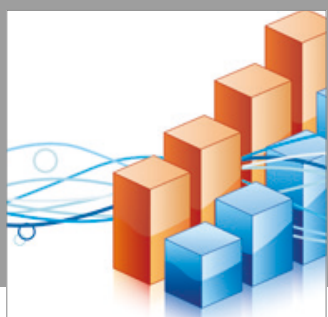

Advances in

Operations Research

vatersals

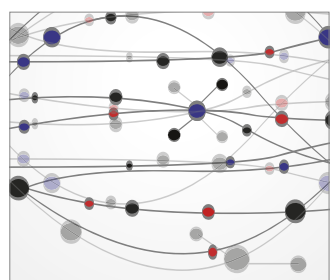

\section{The Scientific} World Journal
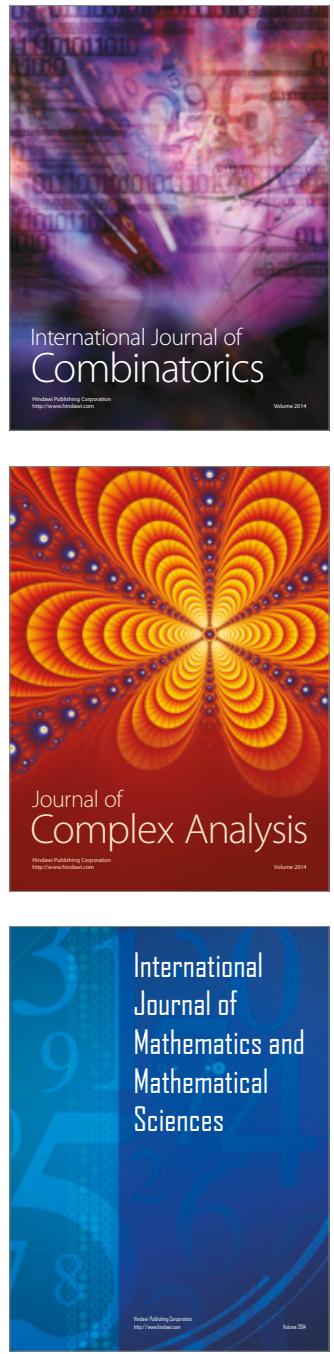
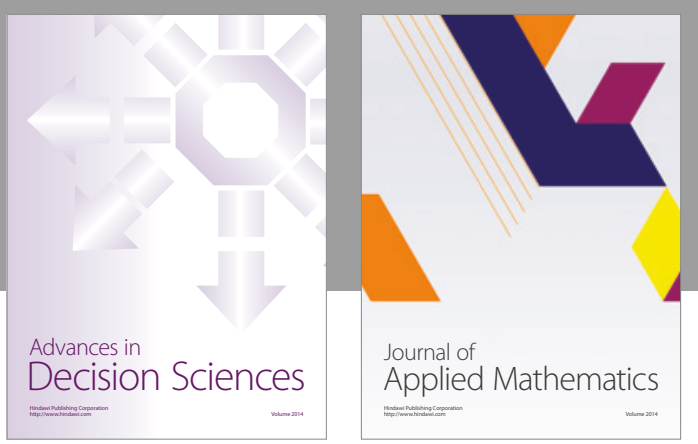

Algebra

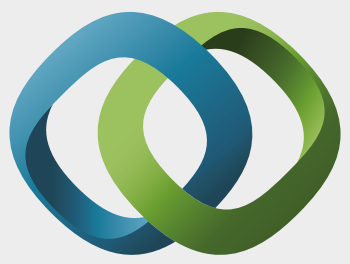

\section{Hindawi}

Submit your manuscripts at

https://www.hindawi.com
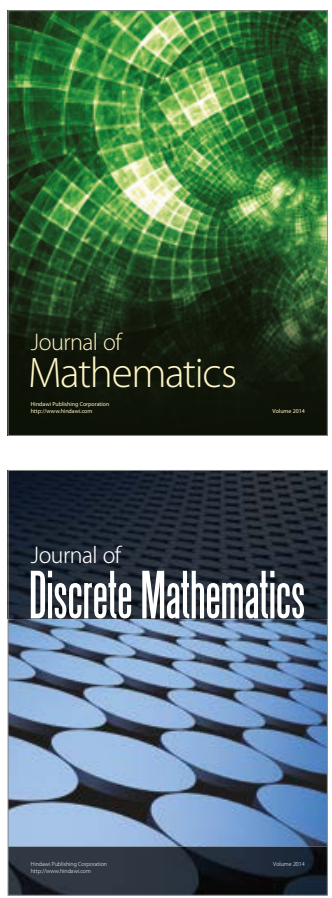

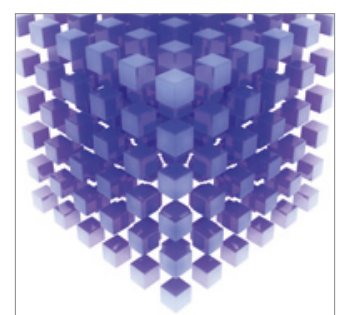

Mathematical Problems in Engineering
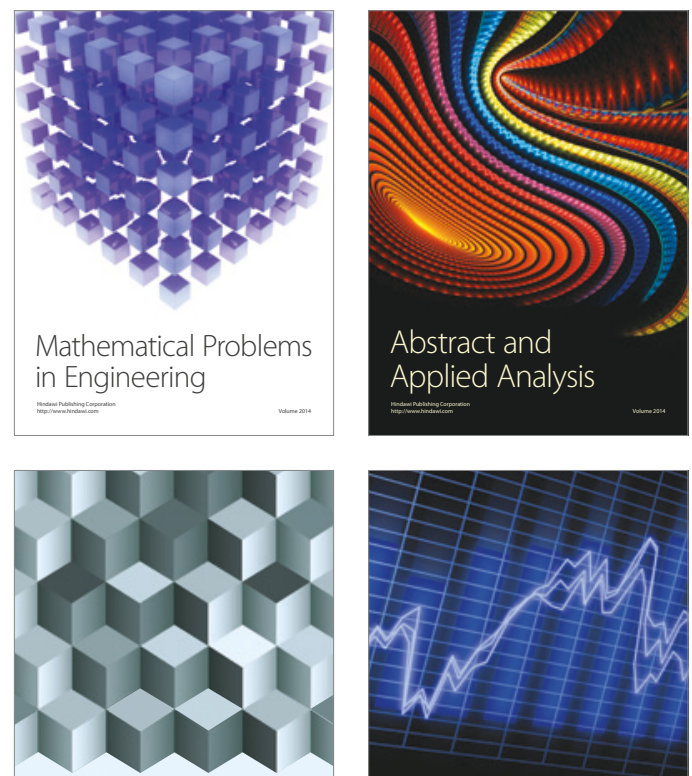

Journal of

Function Spaces

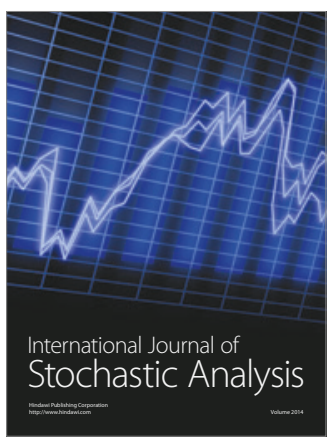

Probability and Statistics
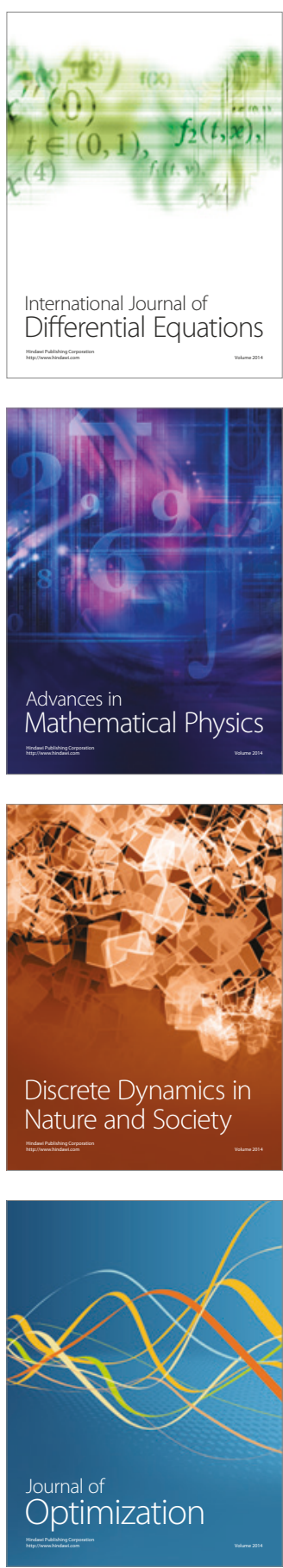